\title{
THE CARDIOVASCULAR RISK IN CUSHING'S SYNDROME
}

\author{
Mariana Dobrescu1, Diana Păun ${ }^{1,2}$, Daniel Grigorie ${ }^{1,2}$, Adina Ghemigian ${ }^{1,2}$, Cătălina Poiană ${ }^{1,2}$ \\ ${ }^{1 " C . I . ~ P a r h o n " ~ N a t i o n a l ~ I n s t i t u t e ~ o f ~ E n d o c r i n o l o g y, ~ B u c h a r e s t ~}$ \\ 2"Carol Davila" University of Medicine and Pharmacy, Bucharest
}

\begin{abstract}
Cushing's syndrome (CS) is a clinical condition resulting from chronic exposure to glucocorticoid excess. Hypercortisolism contributes significantly to the early development of systemic disorders by direct and/or indirect effects. Complications such as obesity, hypertension, diabetes, dyslipidemia, and hypercoagulability cause premature atherosclerosis and increase cardiovascular mortality. These associated abnormalities increase cardiovascular risk not only during the active phase of the disease but also long after the remission of hypercortisolism. Clinical management of these patients should be particularly careful and control of cardiovascular risk factors is necessary for a long period.
\end{abstract}

Keywords: Cushing's syndrome, hypercortisolism, obesity, hypertension, diabetes, dyslipidemia, hypercoagulability, atherosclerosis, cardiovascular risk.

\section{Rezumat}

Sindromul Cushing este rezultatul expunerii cronice la excesul de glucocorticoizi. Hipercortizolismul contribuie semnificativ la apariţia precoce a complicaţiilor sistemice prin efecte directe şi/sau indirecte. Complicaţii ca obezitatea, hipertensiunea, diabetul şi hipercoagulabilitatea produc ateroscleroză prematură şi cresc mortalitatea cardiovasculară. Aceste co-morbidităţi cresc riscul cardiovascular nu numai în timpul perioadei active a bolii, dar şi pe termen lung după remisiunea hipercortizolismului. De aceea, este necesar controlul şi urmărirea pe termen lung a acestei categorii de pacienţi.

Cuvinte cheie: sindromul Cushing, hipercortizolism, obezitate, hipertensiune, diabet, hipercoagulabilitate, ateroscleroză, risc cardiovascular. 


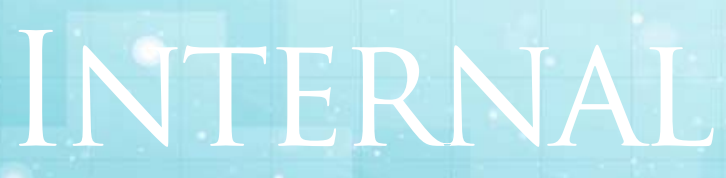

\section{General Reviews}

Endogenous Cushing's syndrome (CS) is the result of chronic exposure to high endogenous levels of glucocorticoids. The most common cause of Cushing's syndrome is the excess secretion of ACTH (80-85\% of cases) produced most commonly by an ACTH-secreting pituitary adenoma (Cushing's disease - CD); another source is the ectopic secretion of ACTH by a neoplasm or, very rarely, by a $\mathrm{CRH}$-secreting tumor. The excessive cortisol secretion can by ACTH-independent (15-20\% of cases) and can be caused by one or more adrenal tumors, bilateral adrenal hyperplasia, adrenal carcinoma, micronodular adrenal dysplasia (Carney syndrome), the presence of abnormal receptors with ACTHindependent macronodular hyperplasia. Exogenous CS is caused by extended treatment with glucocorticoids in high doses (0.8-2\% of cases).

Typically in Cushing's syndrome is the disappearance of the normal circadian rhythm of cortisol secretion, with a maximum concentration in the morning and a minimum level at midnight, and also of the physiological feedback of the hypothalamicpituitary-adrenal axis between cortisol, $\mathrm{ACTH}$ and the hypothalamic peptide, $\mathrm{CRH}$. Even under adequate conditions the diagnosis in CS in often delayed between 2 and 5 years, and thus hypercortisolism causes its effects for a long period of time before diagnosis and treatment. Chronic hypersecretion of cortisol, regardless of etiology, is associated with severe morbidities, especially metabolic and cardiovascular complications, osteoporosis, psychiatric and cognitive disorders, with the impairment of the quality of life and the increase of mortality.

The clinical pattern and the co-morbidities in Cushing's syndrome are characteristic. Specific are the central obesity, muscle atrophy and asthenia, hypertension, glucose intolerance, hyperlipidemia, and hypercoagulability. These complications are only partially reversible after the treatment of the subjacent disease, despite the cure of the hypercortisolism and the regression of clinical manifestations. Comorbidities and complications of the active phase of the disease are persistent for a long term after surgical or medical treatment of $\mathrm{CS}^{(1,2,3,4)}$. Mortality in CS is increased: untreated patients have a 5-year survival rate estimated at $50 \%{ }^{(1,2,3,4)}$; some studies reported a 2-5 times higher mortality vs the reference population, which is due to cardiovascular complications.

The mortality rate decreased significantly after the introduction of transsphenoidal surgery, but normalization of cortisol is not sufficient for the decrease of mortality due to co-existing risk factors, i.e.: cardiovascular risk, the surgery itself, hypoparathyroidism, 


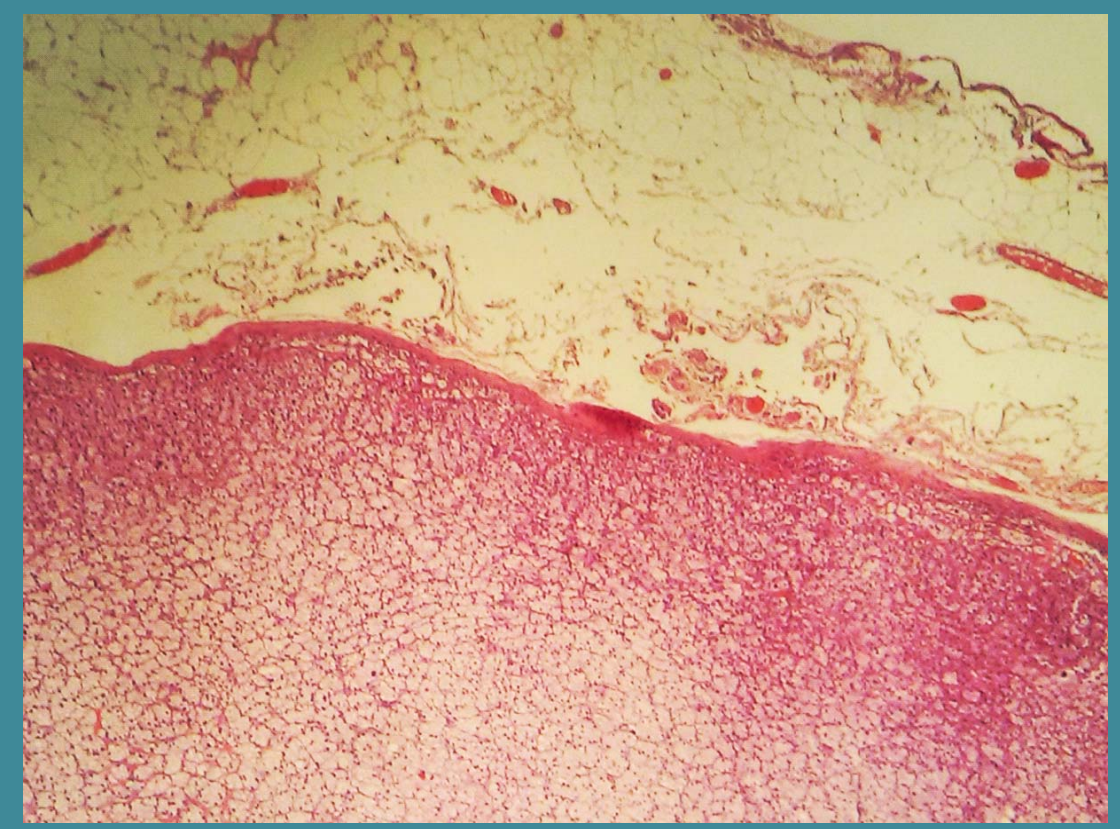

Figure 1. T.M, 49 years old. Adrenal tumor, well encapsulated, without area of invasion or capsule effraction

- age of onset of obesity

- family history of type 2 diabetes

- physical activity

- quantity and quality of daily food

- duration of the exposure to the excess of cortisol

Table 1. Factors which concur to the occurrence of metabolic abnormalities

- diabetes mellitus: $20-47 \%$ of patients

- glucose intolerance: $21-64 \%$

- type 2 DM in subclinical Cushing's syndrome: $1 / 3$ of patients

Table 2. Frequency of carbohydrate metabolism anomalies 
General Reviews

- inhibition of the vasodilator system

- activation of the renin-angiotensin-aldosterone system

- inhibition of the catecholamine catabolism

Table 3. Factors which contribute to the occurrence of hypertension

- reduction of endothelial nitric oxide, oxidative stress, and decrease of vasodilator factors

- endothelial dysfunction with the participation of cytokines, inflammation markers, adhesion molecules

Table 4. The actions of glucocorticoids on the vascular wall

- increase of the vasoconstrictor response to catecholamines and decrease of vasodilation and of prostacyclin synthesis

- increase of angiotensinogen concentration (partially compensated by the decrease of renin secretion)

- participation of aldosterone receptors with secondary hyperaldosteronism in the pathogenesis of hypertension; resulting in hypertrophy of vascular smooth muscle cells with muscle hypertonia and hypertrophy of the media

Table 5. The indirect actions of glucocorticoids on the vascular wall 
patient age at the time point of diagnosis. Therefore the long-term treatment and follow-up (monitoring) of the patients with high cardiovascular risk are required, as this risk persists after the treatment of CS.

\section{Cardiovascular disease in Cushing's syndrome}

Hypercortisolism is associated with exacerbation of cardiovascular risk factors, such as: obesity, glucose intolerance, hypertension, dyslipidemia, hypercoagulability, and the cardiovascular risk remains high even 5 years after the biochemical normalization of the hypercortisolism ${ }^{(5)}$.

Central obesity and visceral adiposity is the characteristic phenotype of CS. Accumulation of visceral adiposity can be massive in Cushing's syndrome and concurs to the dysmetabolic pattern of patients. Metabolic abnormalities involve the participation of cortisol, but also of other factors (Table 1 ).

Obesity is associated with the production of adipokines, which in turn participate to the pathogenesis of vascular, metabolic and inflammatory complications, and also endothelial dysfunction, hypertension, atherosclerosis, and bone remodelling. The increased secretion of leptin, resistin, and pro-inflammatory cytokines (TNF $\alpha$ and IL-6) is associated with the increase of the cardiovascular risk. In addition, leptin increases the enzyme activity of 11 betahydroxysteroid dehydrogenase type 1 (11ßHSD1) which transforms inactive cortisone in cortisol $^{(6)}$. Also leptin and other adipokines, but also humoral factors can stimulate the level of circulating cortisol, thus contributing to visceral obesity and the characteristics of the metabolic syndrome. In contrast, adiponectin - an adipokine with anti- atherogenic and anti-inflammatory activity is decreased in obesity, in the presence of insulin-resistance, and in CS, even 10 years after treatment ${ }^{(7)}$. This unfavourable profile of adipokines contributes to the degree of inflammation persistent in patients with treated CS, resulting in long-term increase of the cardiovascular risk. Central adiposity, characteristic of the metabolic syndrome, and also omental adiposity in Cushing's syndrome, can generate cortisol from inactive cortisone via the $11 \beta \mathrm{HD}$ pathway; in addition, the expression of this enzyme is increased after exposure to cortisol and insulin. This mechanism ensures constant exposure to glucocorticoids specific for omental adiposity, resulting in central adiposity $^{(8)}$.

\section{Alteration of glucose metabolism} (insulin resistance, glucose intolerance, and diabetes mellitus) is another cardiovascular risk factor favoured by hypercortisolism. Opposite to this, people with hyperglycemia can have apparent cortisol increases due to the increase of peripheral sensitivity to glucocorticoids. The pathogenic role of the cortisol in the alteration of glucose metabolism is linked to the effects of the glucocorticoids on gluconeogenesis, on the secretory activity of $\beta$ pancreatic cells, effects on peripheral tissues. The variability of the expression and function of glucocorticoid receptor and the relationship to the insulin resistance in these patients was studied $^{(9,10)}$. Glucose intolerance and diabetes are frequent in Cushing's syndrome and in many studies they reach $69 \%$ of cases (Table 2).

\section{Hypertension in Cushing's syndrome}

In the active period, CS is associated with moderate hypertension, with extended 


\section{INTERNAL}

\section{General Reviews}

evolution, which is persistent after the adequate treatment of the disease.

Patient with hypercortisolism remission, but with persistent hypertension present important morphological and functional cardiac changes compared to non-Cushing hypertensive patients. Hypertension can persist after the remission of Cushing's syndrome, either due to the aggression caused by cortisol in the microcirculation or due to the co-existence with essential hypertension. Hypertension in Cushing's syndrome is multifactorial ${ }^{(11)}$ (Table 3 ). The mechanisms of glucocorticoid-induced hypertension are partially elucidated, but studies showed the relationship with the imbalance between vasodilator and vasoconstrictor factors (nitric oxide, prostacyclin, and endothelin 1), activation of mineralocorticoid receptors, and endothelial dysfunction ${ }^{(17,18,19,20)}$. In the pathogenesis of hypertension in Cushing's syndrome interdependent pathophysiological pathways take part ${ }^{(12,13,14,15,16)}$ :

1. increase of plasma volume, to which the following contribute:

- the mineralocorticoid activity of cortisol, via activation of mineralocorticoid receptors by cortisol, resulting in an apparent excess of mineralocorticoids;

- concomitant secretion of mineralocorticoid hormones; in addition, the increase of the cortisol level can exceed the capacity of $11 \beta$ HSD2 (enzyme which inactivates cortisol), and thus the coupling of cortisol to the mineralocorticoid receptors is favoured, resulting in the increase of the effect of aldosterone with myocardial fibrosis;

- redistribution of sodium in extracellular spaces;

- increase of cardiac output, mediated by epinephrine, which is induced by the increase of the activity of PNMT (phenylethanolamine-N-methyltransferase);

2. increase of peripheral vascular resistance:

- increase of the circulating level of angiotensin II via the increase of hepatic synthesis of angiotensinogen;

- increase of the vascular response to vasoconstrictor stimuli (angiotensin II, catecholamines, vasopressin, erythropoietin);

- inhibition of vasodilator systems (nitric oxide, kinin/kallicrein, prostacyclin);

- inhibition of peripheral catabolism of catecholamines, particularly of norepinephrine;

- direct action of glucocorticoids on cardiovascular receptors; 
- decrease of production of atrial natriuretic peptide (ANP) with decrease of vasodilation via ANP.

The participation of other genetic factors is also studies, considering the polymorphism of glucocorticoid receptors.

Alterations of coagulation are a major cardiovascular risk factor which explains the thromboembolic complications in $10 \%$ in patients with Cushing's syndrome, especially postoperatively ${ }^{(21,22)}$. In CS there are increased levels of Factor VIII, Factor IV and von Willebrand Factor, and also increase of synthesis of PAl-1 (plasminogen activator inhibitor-1) which is the main inhibitor of the fibrinolytic system ${ }^{(21)}$. Glucocorticoids increase the synthesis of fibrinogen, stimulate the endothelial production of von Willebrand Factor ( $v W F$ ), and the pathological increase of circulating vWF causes a hypercoagulability due to the concomitant increase of Factor VIII which is transported in blood by vWF and increase of platelet aggregation. In addition, hypercortisolism is associated with the decrease of fibrinolytic capacity via the increase of PAI-1. Also the increase of homocysteine was described, a factor associated with prothrombotic status ${ }^{(23,24,25,26)}$. In addition, vascular anomalies and endothelial dysfunction, venous stasis due to decreased mobility or extended postoperative immobilization, increased haematocrit and secondary polycythaemia participate in thrombotic complications; polycythaemia can gave an additional role in the "hyperviscosity syndrome" which favours thrombotic complications. Thus the simultaneous presence of prothrombotic factors and venous stasis explains the high incidence of venous thrombosis in patients who are immobilized postoperatively.
Therefore prophylactic anticoagulation is recommended in all patients with surgical indication (transsphenoidal or adrenal). Some specialized centres recommend after adrenalectomy the extension of anticoagulant treatment in the postoperative period for a minimum of 3 months. The coagulation parameters can improve postoperatively, but the hypercoagulability persists without a complete normalization of these, and the risk of thrombosis is maintained and is accentuated by surgical interventions and obesity.

\section{The atherosclerosis risk in Cushing's syndrome}

Hypercortisolism is associated from the first stages with increase of arterial rigidity and acceleration of the atherosclerotic process. Many recent studies indicate - as opposed to older studies - that extended exposure to increased glucocorticoid values induces irreversible vascular changes, thus contributing to the increase of morbidity and mortality of patients with hypercortisolism ${ }^{27}$. 28, 29, 30, 31). Cardiovascular risk factors such as hypertension, obesity, hyperlipidemia, and glucose intolerance have a high prevalence in Cushing's syndrome. Central obesity characteristic in Cushing's syndrome - is associated with the alteration of production of adipokines, which participates in the pathogenetic mechanisms of metabolic and cardiovascular complications. The increase of leptin and resistin, and also of proinflammatory cytokines (tumor necrosis factor-alpha and interleukin-6) is associated with endothelial dysfunction and chronic inflammatory status, characteristic in atherothrombosis; on the other hand, the low level of adiponectin, characteristic in obesity, is associated with insulin resistance. 


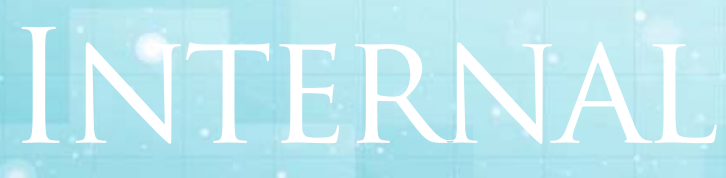

General Reviews

Lipid anomalies were reported in $40-70 \%$ of patients, including those with subclinical disease.

The dyslipidemia from Cushing's syndrome is characterized by the increase of total cholesterol, of LDL- and VLDL-cholesterol, and of triglycerides. The surgical treatment of the disease is generally followed by significant improvement of the lipid profile. Also the medical treatment with ketoconazole - a blocker of cortisol biosynthesis - is also associated with the inhibition of cholesterol biosynthesis and the decrease of the cholesterol plasma level. In contrast, treatment with DDD - adrenolytic drug used in the treatment of adrenal carcinoma or in cases of resistant Cushing's disease - is associated with the increase of the level of total cholesterol, and especially LDL-cholesterol, and requires association with statin-type cholesterol-lowering agents. The excess of glucocorticoid hormones induces vascular alterations with the increase of arterial rigidity, via both direct and indirect effects. The direct actions of glucocorticoids on the vascular wall involve many changes (Table 4).

The indirect actions of glucocorticoids on the vascular wall cause significant changes at this level (Table 5).

All these mechanisms have the final result of vascular remodelling, which affects both large vessels and arterioles.

\section{Subclinical hypercortisolism}

Subclinical hypercortisolism represents the biochemical excess of cortisol, without classic signs and symptoms of manifested hypercortisolism. Classically it is accepted that subclinical Cushing's syndrome is referring to the alteration of the hypothalamic-pituitary-adrenal axis in patients with adrenal masses discovered incidentally, and who do not present signs and symptoms specific for manifested Cushing's syndrome. This simple definition became inadequate in the present time, and additionally certain imaging, clinical and hormone particularities were outlined, which allow the diagnosis of these patients ${ }^{(32,33)}$. The term "adrenal incidentaloma" refers to a group of adrenal masses discovered accidentally during an imaging investigation. The majority of these tumors are benign and are not associated with hormone hyperfunction (cortisol, aldosterone, catecholamines). However a considerable percentage of cases present changes of cortisol secretion, without clinical manifestations specific to Cushing's syndrome. This category is classified as subclinical (or preclinical) Cushing's syndrome, but in the present time there is no consensus regarding its definition, the diagnostic criteria, and the management of these patients ${ }^{(34,35)}$. 
It is considered that subclinical hypercortisolism is present in 5 to $30 \%$ of patients with adrenal masses discovered incidentally (adrenal incidentalomas), which in turn are present in $4-7 \%$ of the adult population. Therefore it is estimated that subclinical hypercortisolism could be present in $0.2-2 \%$ of the adult population; some studies suggest that it is present in $1-10 \%$ of the patients with confirmed diabetes or osteoporosis. Subclinical hypercortisolism is associated with the chronic complications of the manifested excess of cortisol. The most common clinical manifestations are hypertension and type 2 diabetes mellitus, which occur in $2 / 3$ and $1 / 3$ of patients, respectively. It is also associated with cardiovascular and metabolic complications such as endothelial aggression, visceral adiposity, and deregulation of lipid metabolism. All these manifestations increase the cardiovascular risk of these patients, and recent studies have shown the increased incidence of cardiovascular events and of cardiovascular mortality ${ }^{(36,37)}$.

In the present time the optimal strategy for the diagnosis and management of subclinical Cushing's syndrome is not established, as standard biochemical test for CS are unsatisfying for the detection of minor cortisol excess. Most authors consider that is necessary to improve the performance of hormonal evaluation and to define the complete steroid profile. The management of this condition is still empirical, in the absence of long-term studies regarding possible complications. Adrenalectomy or medical treatment is indicated in the absence of conclusive studies regarding the superiority of surgical or non-surgical treatment.

The resolution of hypercortisolism, confirmed biochemically and hormonally, is not associated with the decrease of the cardiovascular risk. The duration of the disease and the duration of the exposure to hypercortisolism are essential for the determination of the cardiovascular risk induced by Cushing's syndrome, and in cases with extended exposure the cardiovascular manifestations are irreversible. After the remission of the disease, the morbidity by cardiovascular diseases remains high for a long period of time. Patients in remission after Cushing's syndrome presents a high incidence of the metabolic syndrome, cardiovascular and cerebrovascular disease; obesity and increased inflammatory markers persist for a long period of time after the treatment for Cushing's syndrome. The persistence of vascular alterations is associated with the persistence of the cardiovascular risk and increased cardiovascular mortality in these patients. Therefore it is essential to diagnose the disease as early as possible and to assess the associated cardiovascular alterations in order to establish an adequate treatment.

\section{Conclusions}

The signs of hypercortisolism onset are similar to the presentation of the metabolic syndrome: central adiposity, glucose intolerance and DM, hypertension. Persistent hypercortisolism is a systemic disease with multiple metabolic and cardiovascular complications which are only partially reversible after the remission of CS. The majority of studies highlight the central role of the cortisol in the development of the cardiovascular disease, but also the relationship with the duration of the exposure to cortisol. The chronic exposure to glucocorticoid excess contributes to the early development of systemic complications via direct and/or indirect effects. Obesity, 
hypertension, diabetes, dyslipidemia, and prothrombotic status cause premature atherosclerosis and increase cardiovascular mortality, which remains high for a long period of time after the remission of the disease. Many studies have shown that the medical and/or surgical treatment of Cushing's syndrome does not significantly decrease the cardiovascular risk, and the control of the cardiovascular risk factors should be a major target in the follow-up of these patients. Therefore the chronic long-term monitoring of the co-morbidities is required.

\section{References}

1. R. Pivonello, M.C. de Martino, M. de Leo,L. Tauchmanovà, A. Faggiano, G. Lombardi, Cushing's syndrome: Aftermath of the cure, Arq Bras Endocrinol Metabol, 51 (2007), pp. 1381-1391.

2. E. Valassi, I. Crespo, A. Santos, S.M. Webb, Clinical consequences of Cushing's syndrome, Pituitary, 15 (2012), pp. 319-329.

3. R.A. Feelders, S.J. Pulgar, A. Kempel, A.M. Pereira, The burden of Cushing's disease: clinical and health-related quality of life aspects, Eur J Endocrinol, 167 (2012), pp. 311-326.

4. E. Valassi, A. Santos, M. Yaneva, M. Toth, C.J. Strasburger, P. Chanson, The European Registry on Cushing's syndrome: 2-year experience. Baseline demographic and clinical characteristics, Eur J Endocrinol, 165 (2011), pp. 383-392.

5. A. Colao, R. Pivonello, S. Spiezia, A. Faggiano, D. Ferone, M. Filippella, Persistence of increased cardiovascular risk in patients with Cushing's disease after five years of successful cure, J Clin Endocrinol Metab, 84 (1999), pp. 2664-2672.

6. Y. Liu, Y. Nakagawa, Y. Wang, R. Li, X. Li, T. Ohzeki, Leptin activation of corticosterone production in hepatocytes may contribute to the reversal of obesity and hyperglycemia in leptin-deficient ob/ob mice, Diabetes, 52 (2003), pp. 1409-1416.

7. M.J. Barahona, N. Sucunza, E. Resmini, J.M. FernándezReal, W. Ricart, J.M. Moreno-Navarrete, Persistent body fat mass and inflammatory marker increases after long-term cure of Cushing's syndrome, J Clin Endocrinol Metab, 94 (2009), pp. 3365-3371.

8. Bujalska IJ, Kumar S, Stewart PM. Does central obesity reflect Cushing's disease of the omentum? Lancet. 1997;349:1210-3.

9. Andrews RC, Herlihy $O$, Livingstone DE. et al. Abnormal cortisol metabolism and tissue sensitivity to cortisol in patients with glucose intolerance. J Clin Endocrinol Metab. 2002;87:5587-93.

10. Reynolds RM, Chapman KE, Seckl JR. et al. Skeletal muscle glucocorticoid receptor density and insulin resistance. JAMA. 2002;287:2505-6.

11. M. De Leo, R. Pivonello, R.S. Auriemma, A. Cozzolino, P. Vitale, C. Simeoli, Cardiovascular disease in Cushing's syndrome: heart versus vasculature, Neuroendocrinology, 92 (2010), pp. 50-54.

12. Giraldi FP, Moro M, Cavagnini F. Study Group on the Hypothalamo-Pituitary-Adrenal Axis of the Italian Society of Endocrinology. Gender-related differences in the presentation and course of Cushing's disease. J Clin Endocr Metab 2003;88:1554-1558.

13. Mancini T, Kola B, Concettoni C, Boscaro M, Mantero F, Arnaldi G. Hypertension in patients with Cushing's syndrome: Evidence for gender difference in $11 \beta$ hydroxysteroid dehydrogenase type 2 activity. The Endocrine Society 85nd Annual Meeting, Philadelphia, P2606, 2003;454.

14. Magiakou MA, Mastrokaros G, Olfield EA, Gomez MT, Doppman JL, Cutler GBJ, Nieman LK. Chrousos GP Cushing's syndrome in children and adolescents: Presentation, diagnosis and therapy. New England J Med 1994;331:629-636.

15. Biglieri EG, Kater CE, Mantero F. Adrenocortical forms of human hypertension. In: Laragh, Brenner (Eds), Hypertension, 2nd edn. Raven Press, 1995:2145.

16. Arnaldi G, Mancini T, Tirabassi G. et al. Advances in the 
epidemiology, pathogenesis, and management of Cushing's syndrome complications. J Endocrin Invest. 2012;35:434-38.

17. Magiakou MA, Smyrnaki P, Chrousos GP: Hypertension in Cushing's syndrome. Best Pract Res Clin Endocrinol Metab 2006;20:467-482.

18. Pecori Giraldi F, Toja PM, De Martin M, Maronati A, Scacchi M, Omboni S, Cavagnini F, Parati G: Circadian blood pressure profile in patients with active Cushing's disease and after long-term cure. Horm Metab Res 2007;39:908-914.

19. Muiesan ML, Lupia M, Salvetti M, Grigoletto C, Sonino $N$, Boscaro M, Rosei EA, Mantero F, Fallo F: Left ventricular structural and functional characteristics in Cushing's syndrome. J Am Coll Cardiol 2003;41:2275-2279.

20. Pereira AM, Delgado V, Romijn JA, Smit JW, Bax JJ, Feelders RA: Cardiac dysfunction is reserved upon successful treatment of Cushing's syndrome. Eur J Endocrinol 2010;162:331-340.

21. B. Van Zanne,E. Nur,A. Squizzato,O.M. Dekkers,M.T. Twickler,E. Fliers, Hypercoagulable state in Cushing's syndrome: a systematic review, J Clin Endocrinol Metab, 94 (2009), pp. 2743-2750.

22. L. Manetti,F. Bogazzi,C. Giovannetti,V. Raffaelli,M. Genovesi,G. Pellegrini, Changes in coagulation indexes and occurrence of venous thromboembolism in patients with Cushing's syndrome: results from a prospective study before and after surgery, Eur J Endocrinol, 163 (2010), pp. 783-791.

23. Ermetici F, Malavazos AE, Corbetta S, Eller-Vainicher C, Cannavò S, Corsi MM, Ambrosi B: Soluble adhesion molecule levels in patients with Cushing's syndrome before and after cure. J Endocrinol Invest 2008;31:389-392.

24. Kristo $C$, Ueland T, Godang K, Aukrust P, Bollerslev J: Biochemical markers for cardiovascular risk following treatment in endogenous Cushing's syndrome. J Endocrinol Invest 2008;31:400-405.

25. Boscaro M, Sonino N, Scarda A, Barzon L, Fallo F, Sartori MT, Patrassi GM, Girolami A: Anticoagulant prophylaxis markedly reduces thromboembolic complications in Cushing's syndrome. J Clin Endocrinol Metab 2002;87:3662-3666.

26. Terzolo M, Allasino B, Bosio S, Brusa E, Daffara $F$, Ventura M, Aroasio E, Sacchetto G, Reimondo G, Angeli A, Camaschella C: Hyperhomocysteinemia in patients with Cushing's syndrome. J Clin Endocrinol Metab 2004;89:3745-3751.
27. Faggiano $A$, Melis $D$, Alfieri $R$, De Martino $M$, Filippella M, Milone F, Lombardi G, Colao A, Pivonello R: Sulfur amino acids in Cushing's disease: insight homocysteine and taurine levels in patients with active and cured disease. J Clin Endocrinol Metab 2005;90:6616-6622.

28. M.J. Barahona,E. Resmini,D. Viladés,G. Pons-Lladó,R. Leta,T. Puig, Coronary artery disease detected by multislice computed tomography in patients after longterm cure of Cushing's syndrome, J Clin Endocrinol Metab, 98 (2013), pp. 1093-1099.

29. Baykan M, Erem C, Gedikli O. et al. Impairment of flowmediated vasodilatation of brachial artery in patients with Cushing's Syndrome. Endocrine. 2007;31:300-4.

30. Prázný M, Jezková J, Horová E. et al. Impaired microvascular reactivity and endothelial function in patients with Cushing's syndrome: influence of arterial hypertension. Physiol Res. 2008;57:13-22.

31. Neary NM, Booker OJ, Abel BS. et al. Hypercortisolism is associated with increased coronary arterial atherosclerosis: analysis of noninvasive coronary angiography using multidetector computerized tomography. J Clin Endocrinol Metab. 2013;98:2045-52.

32. Schneider HJ, Dimopoulou C, Stalla GK, Reincke M \& SchopohlJ. Discriminatory value of signs and symptoms in Cushing's syndrome revisited: what has changed in 30 years? Clinical Endocrinology 201378 153-154.

33. Shen J, Sun M, Zhou B \& Yan J. Nonconformity in the clinical practice guidelines for subclinical Cushing's syndrome: which guidelines are trustworthy? European Journal Endocrinology 2014171 421-431.

34. Mantero F, Terzolo M, Arnaldi G, Osella G, Masini AM, Alì A, Giovagnetti $M$, Opocher $G \&$ Angeli $A$. A survey on adrenal incidentaloma in Italy. Study Group on Adrenal Tumors of the Italian Society of Endocrinology. Journal of Clinical Endocrinology and Metabolism 200085 637-644.

35. Terzolo M, Pia A, Alì A, Osella G, Reimondo G, Bovio S, Daffara F, Procopio M, Paccotti P, Borretta G et al. Adrenal incidentaloma: a new cause of the metabolic syndrome? Journal of Clinical Endocrinology and Metabolism 200287 998-1003.

36. Chiodini I. Clinical review: diagnosis and treatment of subclinical hypercortisolism. Journal of Clinical Endocrinology and Metabolism 201196 1223-1236.

37. Shen J, Sun M, Zhou B \& Yan J. Nonconformity in the clinical practice guidelines for subclinical Cushing's syndrome: which guidelines are trustworthy? European Journal Endocrinology 2014171 421-431 